\title{
Effect of bull performance on progeny early growth and genetic relationships between bull and progeny traits
}

\author{
S Aktar ${ }^{1}$, AKFH Bhuiyan', NG Saha ${ }^{2}$ and MA Hoque* ${ }^{1}$ \\ ${ }^{1}$ Department of Animal Breeding and Genetics, Bangladesh Agricultural University, Mymensingh 2202, \\ Bangladesh; ${ }^{2}$ Department of General Animal Science and Nutrition, Patuakhali Science and Technology \\ University, Patuakhali, Bangladesh
}

\begin{abstract}
Records on four bulls and 96 of their progeny born from 2005 to 2011 with pedigree information were used to estimate the impact of bull performance on progeny early growth and the genetic relationships between traits of bull and their progeny. Traits included in this study were metabolic body weight, feed intake and residual feed intake (RFI) for bull performance and birth weight and average daily gain for progeny performance. The variance and covariance components were estimated by the REML method with the VCE computer program. The metabolic body weight of breeding bulls ranged from 92.88 \pm 1.22 to $106.05 \pm 2.28 \mathrm{~kg}$. The average daily feed intake of breeding bulls differed significantly $(p<0.05)$. The RFI of breeding bulls were ranged from $-0.57 \pm 0.07$ to $0.54 \pm 0.06 \mathrm{~kg} / \mathrm{day}$. It has been found that the RFI values of two bulls were negative and the other two bulls were positive. The mean values for birth weight of calves produced from different breeding bulls ranged from $16.15 \pm 2.01$ to $17.71 \pm 1.89 \mathrm{~kg}$. Effects of breeding bulls on birth weight and average daily gain of male calves were highly significant $(p<0.01)$. Mean values for birth weight and average daily gain of female calves were affected also significantly $(p<0.05)$ among breeding bulls. Estimated heritability for birth weight was moderate $(0.30)$ and for average daily gain was low (0.26). The genetic correlation between metabolic body weight of bulls and birth weight of their progeny was strong $\left(r_{g}=0.52\right)$, whereas feed intake of bulls with birth weight and average daily gain of their progeny were moderate $(0.43 \pm 0.21$ and $0.40 \pm 0.23$, respectively). Low but favorable negative genetic correlation $\left(r_{g}=-0.10\right)$ was observed between RFI of bulls with average daily gain of their progeny. Estimated moderate heritability indicated that variation exist on average daily gain of calves. The negative genetic correlation between RFI of bulls and average daily gain of their progeny indicated that it was possible to improve simultaneously RFI of breeding bulls and daily gain of their progeny.
\end{abstract}

Key words: Residual feed intake, heritability, genetic correlation

Bangladesh Animal Husbandry Association. All rights reserved.

Bang. J. Anim. Sci. 2011. 40 (1-2): 1-7

\section{Introduction}

Cattle farming and its development has ever ending need in Bangladesh as they are inseparable and integral part of agricultural farming system in Bangladesh. In the country, there are about 22.87 million cattle, contributing more than $2.32 \%$ to the national GDP (BBS, 2009). About $20 \%$ people of the country are directly or indirectly engaged in livestock and poultry business. Artificial insemination of cows has become popular in Bangladesh following significant achievement in improving the cattle breeding system. Different government and non government organizations are trying to spread it all over the country. However, superior bull selection is very much essential to get superior progeny for both of natural mating and artificial insemination.
Providing feed to cattle is the single largest expense $(60-85 \%$ in feedlot beef cattle; Robinson and Oddy 2004) in most cattle production enterprises and thus any effort at improving the efficiency of utilization of animals will help to reduce production costs. Selection for extra feed intake of an animal, that is, Residual feed intake (RFI) may be an alternative measure of feed efficiency (Arthur et al. 2001) and bull selection based on RFI may be well approach to improve whole herd production efficiency (Hoque et al. 2009). RFI may be defined as actual feed intake minus the expected feed intake of each animal was first proposed as an alternate measure of feed efficiency by Koch et al. (1963). The measure of RFI is largely independent of growth and maturity patterns (Okine et al. 2004). As 
Aktar et al. (201 1) Bang. J. Anim. Sci. 40 (1\&2): 1 - 7

heritability estimates range from 0.16 to 0.43 (Herd et al. 2003 and Hoque et al. 2004) the concept of RFI can be used to identify efficient animals.

Estimates of heritability and genetic correlations are essential population parameters required in animal breeding research and in the design and application of practical animal breeding program. These genetic parameters represent the characteristic of a population in which they were estimated and they may be changed over time due to selection and management decisions. The opportunity to improve whole-herd production efficiency through exploitation of genetic variation in feed efficiency traits is dependent not only on the existence of genetic variation in bulls but also on its genetic relationship with their progeny traits. Hoque et al. (2005) estimated the relationships between feed efficiency traits of bulls and carcass traits of their progeny tested at test station and also at field level. However, the estimates of relationships between bull performance traits and progeny early growth traits are also very important to select superior breeding bulls. Considering the above fact in mind, the present study was conducted to estimate the effect of performance of breeding bull on progeny early growth and genetic relationship between bull and progeny traits in our country.

\section{Materials and Methods}

\section{Experimental animals and period}

The experiment was conducted at the artificial insemination ( $\mathrm{Al}$ ) center and the dairy farm of Bangladesh Agricultural University (BAU), Mymensingh. Four breeding bulls at the artificial insemination centre and on 96 of their progeny at the BAU dairy farm produced from those breeding bulls constituted the experimental animals. Breeding bulls were one Sindhi cross (ID 122), two Friesian crosses (ID 131 and 2858) and one Sahiwal cross (ID 143). Bull (feed intake and body weight) data and progeny (weight at birth and at 3-month of age) data were collected during the period from January to December, 2010. However, calves produced from the studied breeding bulls during the period from 2005 to 2009 were also collected from the herd book maintained at the dairy farm to increase the number the records in the analysis.

\section{Bull management and feeding}

The bulls were stall-fed. They were provided $50 \%$ green grass and $50 \%$ straw on the basis of weight plus $1 \mathrm{~kg}$ concentrate feed per day. The concentrate feeds were supplied twice daily in the morning and evening. A mixture of mustard oil cake, wheat bran and common salt was used as concentrate feed. Water also provided ad libitum. Monthly body weights of breeding bulls were recorded using the portable weighing balance. Sheds were cleaned and washed with water in the morning and in the afternoon sheds was cleaned and washed again before feeding. Animals were bathed once in a day. Bulls were kept out of the sheds for free moving and light exercise for about two hours daily in the morning. Vaccination and medication were performed regularly.

\section{Calf management}

The calves were reared in calf pen at the calves' shed of BAU dairy farm. They were provided green grass and water ad libitum. The concentrate feeds were also supplied to them twice daily in the morning and evening. Regular vaccination and medication were performed. In general, ear tag was used for identification of calves, however, in some cases neck band were used for new born calves.

\section{Bull Performance Data}

Bull performance traits were average daily feed intake, metabolic body weight and RFI. Daily feed intake was measured by the difference between supplied and leftover feed. Metabolic body weight was calculated as MBW, raised to the power of $0.75\left(\mathrm{MBW}^{0.75}\right)$. The RFI was estimated as the difference between actual feed intake and that predicted from single trait analysis for daily feed intake with metabolic body weight using statistical analysis system (SAS, 1998) software as described by Hoque and Oikawa (2004). RFI was calculated as:

$\mathrm{RFI}=\mathrm{FI}-\mathrm{MWT} \times \beta_{\mathrm{w}}-$ Intercept

where, $\mathrm{RFI}=$ residual feed intake, $\mathrm{FI}=$ daily feed intake, $\mathrm{MBW}=$ metabolic body weight, $\beta_{\mathrm{w}}$, regression coefficients of animal's FI on MBW.

\section{Progeny Performance Data}

The birth weight and 3-month weight records on 53 male and 43 female calves (total 96) were recorded. The average daily weight gain of 


\section{Breeding bulls and progeny early growth}

calves up to 3-month of age were calculated. The average daily gain for calves was calculated from the difference between birth and 3-months weight divided by the number of days.

\section{Statistical analysis}

The analyses of variances were estimated using the Statistical Analysis System (SAS, 1998) computer program. For estimating the heritability and genetic correlation a pedigree file was constructed. The total number of animals in pedigree file, including testing animals, was 184 in the pedigree file. The covariance for genetic correlation was estimated by the Residual Maximum Likelihood (REML) method with the Variance Component Estimate program (Neumarier and Groeneveld 1998). The covariance components were estimated in a series of two-trait animal models (one bull trait and one progeny trait). The covariance structure for additive genetic effects of animals and residual effects is described below:

$\operatorname{Var}\left(\begin{array}{l}a_{1} \\ a_{2} \\ e_{1} \\ e_{2}\end{array}\right)=\left[\begin{array}{cccc}A \sigma_{a 1}^{2} & A \sigma_{a 12} & \mathbf{0} & \mathbf{0} \\ & A \sigma_{a 2}^{2} & \mathbf{0} & \mathbf{0} \\ & & I \sigma_{e 1}^{2} & I \sigma_{e 12} \\ s y m . & & & I \sigma_{e 2}^{2}\end{array}\right]$

where $a_{1}$ and $a_{2}$ are the vectors of additive genetic effects of animal for a bull trait and a progeny trait, respectively, and $e_{1}$ and $e_{2}$ are the residual effects for them. $A$ is the numerator relationship matrix consisting of the genetic relationships between animals. $\sigma^{2}{ }_{a 1}$ and $\sigma^{2}{ }_{a 2}$ are the additive genetic variances for a bull trait and a progeny trait, respectively, and $\sigma^{2}{ }_{a 12}$ is the additive covariance for them. $\sigma^{2}{ }_{\mathrm{e} 1}$ and $\sigma_{\mathrm{e} 2}^{2}$ are the residual variances for a bull trait and a progeny trait, respectively, and $\sigma^{2}{ }_{a 12}$ is the residual covariance for them. Since the two traits were recorded on different animals. The $\sigma^{2}{ }_{\text {a12 }}$ was assumed to be zero.

\section{Results}

\section{Bull performance}

The average metabolic body weight, daily feed intake and RFI with their standard errors of breeding bulls of Al center are presented in Table 1. The metabolic body weight ranged from $92.88 \mathrm{~kg}$ for Sahiwal cross (ID 143) to 106.05 $\mathrm{kg}$ for Sindhi cross (ID 122). Bull bearing ID 2858 (Friesian cross) consumed the highest amount of feed $(24.82 \pm 2.66 \mathrm{~kg} /$ day $)$, while Sahiwal cross consumed the lowest $(22.85 \pm 2.88$ $\mathrm{kg} /$ day). Average daily feed intake of other two bulls were $24.14 \pm 2.77 \mathrm{~kg}$ (Sindhi cross) and $23.97 \pm 2.87 \mathrm{~kg}$ (Friesian cross, ID 131), respectively. The RFI tended to be the highest $(0.54 \pm 0.06 \mathrm{~kg} /$ day $)$ for Friesian cross bearing ID 2858 and the lowest $(-0.37 \pm 0.07 \mathrm{~kg} /$ day $)$ for Sahiwal cross.

\section{Progeny performance}

The mean values with standard errors for birth weight of calves produced from different breeding bulls are presented in Table 2. Average birth weight of 28 calves produced from Sindhi cross was $16.43 \pm 2.50 \mathrm{~kg}, 35$ calves produced from Friesian cross (ID 131) was $17.51 \pm 2.09 \mathrm{~kg}$, 26 calves produced from Sahiwal cross was $16.15 \pm 2.01 \mathrm{~kg}$ and 7 calves produced from Friesian cross (ID 2858) was $17.71 \pm 1.89 \mathrm{~kg}$. The average daily gain of calves produced from Friesian cross bulls were significantly higher (422.86 40.86 and $410.71 \pm 13.67 \mathrm{~g} /$ day, for bulls bearing ID 131 and 2858, respectively) than those produced from Sindhi and Sahiwal cross bulls $(360.89 \pm 29.44$ and $384.81 \pm 27.02 \mathrm{~g} /$ day, respectively). Average birth weights and average daily gains of males produced from different bulls are shown in Table 3. The average birth weight of 13 calves produced from Sindhi cross was 17.15 $\mathrm{kg}, 18$ calves which produced from Friesian cross (ID 131) was $17.94 \mathrm{~kg}, 18$ calves produced from Sahiwal cross was $16.11 \mathrm{~kg}$ and 4 calves produced from Friesian cross (ID 2858) was $18.25 \mathrm{~kg}$. The mean birth weights of calves produced from Friesian crosses (ID 131 and ID 2858) were significantly higher $(p<0.05)$ than Sahiwal cross. The average daily gain is expressed in $\mathrm{g} /$ day. From the study it was observed that the average daily gain of male calves produced from Friesian crosses were also significantly higher $(p<0.05)$ than others.

Mean birth weights of female calves produced from different breeding bulls are presented in Table 4. From this Table, it has been found that the mean birth weight ranged from $15.80 \pm 2.37$ $\mathrm{kg}$ for Sindhi cross bearing ID 122 to $17.06 \pm 1.95$ $\mathrm{kg}$ for Friesian cross bearing ID 131. Significantly higher $(p<0.05)$ average daily gain was found in female calves produced from Friesian crosses (424.12 and $411.67 \mathrm{~g} /$ day for bulls bearing ID 131 and ID 2858, respectively). 
Aktar et al. (201 1) Bang. J. Anim. Sci. 40 (1\&2): 1 - 7

\section{Heritability and genetic correlation}

Heritability estimates for birth weight and average daily gain and genetic correlations between progeny and bull traits are presented in Table 5. Estimated heritability was moderate $(0.30 \pm 0.20)$ for birth weight and low $(0.26 \pm 0.19)$ for average daily gain. The genetic correlation between birth weight of calves and metabolic body weight of bull was high $\left(r_{g}=0.52\right)$. The daily feed intake of bulls was moderately correlated with birth weight $(0.43 \pm 0.21)$ and average daily gain $(0.40 \pm 0.23)$ of their progeny. Low but negative genetic correlation was observed between average daily gain of calves and RFI of bulls $\left(r_{g=-0.10}\right)$.

Table 1. Average metabolic body weight, daily feed intake and RFI of different breeding bulls maintained at Al center

\begin{tabular}{lccccc}
\hline \multirow{2}{*}{ Bull ID } & \multirow{2}{*}{ Genotype } & \multirow{2}{*}{ Initial age of bull } & \multicolumn{3}{c}{ Mean \pm SE* } \\
\cline { 3 - 6 } & & & MBW $(\mathrm{kg})$ & Fl $(\mathrm{kg} /$ day $)$ & RFI $(\mathrm{kg} / \mathrm{day})$ \\
\hline 122 & Sindhi cross & 8.50 years & $106.05 \pm 2.2$ & $24.14^{\mathrm{b}} \pm 2.77$ & $-0.37 \pm 0.07$ \\
\hline 131 & Friesian cross & 8.25 years & $97.10 \pm 1.62$ & $23.97^{\mathrm{b}} \pm 2.87$ & $0.31 \pm 0.05$ \\
\hline 143 & Sahiwal cross & 4.5 years & $92.88 \pm 1.22$ & $22.85^{\mathrm{a}} \pm 2.88$ & $-0.29 \pm 0.07$ \\
\hline 2858 & Friesian cross & 5.4 years & $102.36 \pm 1.31$ & $24.82^{\mathrm{C}} \pm 2.66$ & $0.54 \pm 0.06$ \\
\hline
\end{tabular}

*322 observations were taken in 322 days on each bull $(n=322)$; Means with different superscript in the same column differ significantly $(p<0.05)$; ID, identity; SE, standard error; MBW, metabolic body weight; $\mathrm{FI}$, feed intake; RFI, residual feed intake

Table 2. Average birth weight and average daily gain of calves at BAU dairy farm produced from different breeding bulls

\begin{tabular}{lccccc}
\hline \multirow{2}{*}{ Bull ID } & \multirow{2}{*}{ Genotype } & No. & \multicolumn{3}{c}{ Mean \pm SE } \\
\cline { 3 - 6 } & & observations & BWT $(\mathrm{kg})$ & FWT $(\mathrm{kg})$ & ADG $(\mathrm{g} /$ day $)$ \\
\hline 122 & Sindhi cross & 28 & $16.43 \pm 2.50$ & $48.91^{\mathrm{b}} \pm 2.87$ & $360.89^{\mathrm{b}} \pm 29.49$ \\
\hline 131 & Friesian cross & 35 & $17.51 \pm 2.09$ & $55.57^{\mathrm{a}} \pm 2.45$ & $422.86^{\mathrm{a}} \pm 32.34$ \\
\hline 143 & Sahiwal cross & 26 & $16.15 \pm 2.01$ & $50.78^{\mathrm{b}} \pm 2.34$ & $384.81^{\mathrm{b}} \pm 27.02$ \\
\hline 2858 & Friesian cross & 7 & $17.71 \pm 1.89$ & $54.67^{\mathrm{a}} \pm 2.14$ & $410.71^{\mathrm{a}} \pm 13.67$ \\
\hline
\end{tabular}

Means with different superscript in the same column differ significantly $(p<0.05)$; Bull ID, bull identity; SE, standard error; BWT, birth weight; FWT, final (3-m of age) weight; ADG, average daily gain.

Table 3. Effect of breeding bulls on birth weight and average daily gain of male calves

\begin{tabular}{llcccc}
\hline \multirow{2}{*}{ Bull ID } & \multirow{2}{*}{ Genotype } & \multirow{2}{*}{ No. Calves } & \multicolumn{3}{c}{ Mean \pm SE } \\
\cline { 3 - 5 } & & & BWT $(\mathrm{kg})$ & FWT $(\mathrm{kg})$ & ADG $(\mathrm{g} /$ day $)$ \\
\hline 122 & Sindhi cross & 13 & $17.15^{\mathrm{ab}} \pm 2.54$ & $49.45^{\mathrm{b}} \pm 2.67$ & $358.84^{\mathrm{c}} \pm 23.64$ \\
\hline 131 & Friesian cross & 18 & $17.94^{\mathrm{a}} \pm 2.18$ & $55.89^{\mathrm{a}} \pm 2.31$ & $421.67^{\mathrm{a}} \pm 22.08$ \\
\hline 143 & Sahiwal cross & 18 & $16.11^{\mathrm{b}} \pm 1.97$ & $50.96^{\mathrm{b}} \pm 2.10$ & $387.22^{\mathrm{b}} \pm 19.93$ \\
\hline 2858 & Friesian cross & 4 & $18.25^{\mathrm{a}} \pm 1.26$ & $55.15^{\mathrm{a}} \pm 1.76$ & $410.00^{\mathrm{a}} \pm 11.54$ \\
\hline
\end{tabular}

Means with different superscript(s) in the same column differ significantly $(p<0.01)$; ID, identity; SE, standard error; BWT, birth weight; FWT, final (3-m of age) weight; ADG, average daily gain.

Table 4. Effect of breeding bulls on birth weight and average daily gain of female calves

\begin{tabular}{lccccc}
\hline \multirow{2}{*}{ Bull ID } & \multirow{2}{*}{ Genotype } & \multirow{2}{*}{ No. of calves } & \multicolumn{2}{c}{ Mean \pm SE } \\
\cline { 3 - 6 } & & & BWT $(\mathrm{kg})$ & FWT $(\mathrm{kg})$ & ADG $(\mathrm{g} /$ day $)$ \\
\hline 122 & Sindhi cross & 15 & $15.80^{\mathrm{b}} \pm 2.37$ & $48.44^{\mathrm{b}} \pm 2.56$ & $362.67^{\mathrm{b}} \pm 19.36$ \\
\hline 131 & Friesian cross & 17 & $17.06^{\mathrm{a}} \pm 1.95$ & $55.23^{\mathrm{a}} \pm 2.14$ & $424.12^{\mathrm{a}} \pm 24.97$ \\
\hline 143 & Sahiwal cross & 8 & $16.25^{\mathrm{ab}} \pm 2.25$ & $50.39^{\mathrm{b}} \pm 2.45$ & $379.37^{\mathrm{b}} \pm 21.15$ \\
\hline 2858 & Friesian cross & 3 & $17.00^{\mathrm{a}} \pm 2.65$ & $54.05^{\mathrm{a}} \pm 2.76$ & $411.67^{\mathrm{a}} \pm 19.92$ \\
\hline
\end{tabular}

Means with different superscript(s) in the same column differ significantly $(p<0.01)$; ID, identity; SE, standard error; BWT, birth weight; FWT, final (3-m of age) weight; ADG, average daily gain 


\section{Breeding bulls and progeny early growth}

Table 5. Heritability of progeny traits and genetic correlations between progeny and bull traits

\begin{tabular}{ccccc}
\hline $\begin{array}{c}\text { Progeny } \\
\text { traits }\end{array}$ & $\mathrm{h}^{2} \pm \mathrm{SE}$ & \multicolumn{3}{c}{ Bull traits, $\mathrm{r}_{\mathrm{g}} \pm \mathrm{SE}$} \\
\cline { 3 - 5 } BWT & 0.30 & 0.52 & 0.43 & 0.08 \\
& \pm 0.20 & \pm 0.28 & \pm 0.21 & \pm 0.22 \\
\hline \multirow{2}{*}{ FWT } & 0.24 & 0.40 & 0.45 & 0.11 \\
& \pm 0.21 & \pm 0.19 & \pm 0.22 & \pm 0.23 \\
\hline \multirow{2}{*}{ ADG } & 0.26 & 0.37 & 0.40 & -0.10 \\
& \pm 0.19 & \pm 0.24 & \pm 0.23 & \pm 0.18 \\
\hline
\end{tabular}

$\mathrm{h}^{2} \pm \mathrm{SE}$, heritability with standard error; $\mathrm{r}_{\mathrm{g}} \pm \mathrm{SE}$, genetic correlation with standard error; BWT, birth weight; ADG, average daily gain; MBW, metabolic body weight; $\mathrm{FI}$, feed intake; FWT, final (3-m of age) weight; RFI, residual feed intake.

\section{Discussion}

\section{Bull performance}

The estimated feed intake of four breeding bulls in the present study was $24.14,23.97,22.85$ and $24.82 \mathrm{~kg} /$ day, respectively, which are in agreement with the findings by Korver et al. (1991). The mean value for metabolic body weight of breeding bulls ranged from $92.88 \pm 1.22 \mathrm{~kg}$ to $106.05 \pm 2.28 \mathrm{~kg}$. Mean values for metabolic body weight was $78.88 \pm 0.23 \mathrm{~kg}$ estimated by Hoque et al. (2006) on Japanese Black bulls. In the present study, mean value of RFI ranged from $-0.37 \pm 0.07$ to $0.54 \pm 0.06$ $\mathrm{kg} /$ day. The mean value for RFI ranged from 1.98 (most efficient) to 2.05 (least efficient) $\mathrm{kg}$ of dry matter per day on 514 Japanese Black bulls by Hoque et al. (2009). The present findings are within the range of the estimates reported by them.

The negative RFI value indicates higher efficiency of an animal for feed utilization. The RFI estimates in the present study were negative for Sindhi and Sahiwal cross bred bull, however, positive for Friesian cross bred bulls. Hoque et al. (2006) estimated RFI for Japanese Black cattle to be $-2.21 \mathrm{~kg} /$ day in young bulls. The variation in RFI values probably reflects differences between the breeds, age and management of bulls.

\section{Progeny performance}

In the present study, the birth weight of calves at the BAU dairy farm produced from studied breeding bulls ranged from $16.15 \pm 2.01 \mathrm{~kg}$ to $17.51 \pm 2.09 \mathrm{~kg}$. Nahar et al. (1992) observed the birth weight of different genetic group such as Sahiwal $\times$ Local, Sindhi $x$ Local, Jersey $\times$ Local and Holstein $\times$ Local cross bred to be $17.6 \pm 0.3,16.1 \pm 0.2,17.7 \pm 0.2$ and $21.4 \pm 0.2 \mathrm{~kg}$, respectively. The estimated birth weight observed by them is more or less similar with the present study. The Friesian cross and their progenies have the highest body weight and birth weight than other two breeds. This might be due to genetic effect and usually manifested in heterosis.

Deb (2004) conducted an experiment using data on Local, Friesian $x$ Local, Jersey $x$ Local cattle maintained at Central Cattle Breeding and Dairy Farm, Savar, Dhaka to estimate genetic parameters for birth weight. The average birth weight was found as $15.87 \pm 0.44 \mathrm{~kg}$ in local, which is close to the result. According to sex, birth weight for male calves was $17.15 \pm 2.25 \mathrm{~kg}$ and for female calves was $16.46 \pm 2.19 \mathrm{~kg}$ found in the present study. Khan et al. (1992) analyzed birth weight records on more than 6000 Sahiwal cows. They reported that the mean value for birth weight to be $20.04 \mathrm{~kg}$.

The mean values for average daily gain in the present study (ranged from $0.36 \pm 0.02$ to $0.42 \pm 0.03 \mathrm{~kg} /$ day) was much lower than those for Japanese Black cattle $(1.23 \pm 0.01 \mathrm{~kg} /$ day $)$ analyzed by Hoque et al. (2006). Other study has shown that the mean value of $0.85 \mathrm{~kg} /$ day on 740 Japanese Black bulls by Hoque et al. (2005). Korver et al. (1991) conducted an experiment and estimated the mean value for average daily gain of cattle to be $0.66 \mathrm{~g} /$ day

\section{Heritability and genetic correlation}

Estimated heritability for birth weight in the present study was moderate $(0.30 \pm 0.20)$. Oikawa et al. (2000) estimated the heritability ranged from 0.20 to 0.38 for growth traits, which supports the present result. Deb (2004) conducted an experiment using data on Local, Friesian $x$ Local, Jersey $x$ Local cattle maintained at Central Cattle Breeding and Dairy Farm, Savar, Dhaka to estimate genetic parameters for birth weight. They estimated heritability of birth weight to be $0.37,0.50$ and 0.49 in Local, Friesian $x$ Local, Jersey $x$ Local cattle, respectively. The heritability of birth weight in present study is more or less similar with the literature results cited. Das et al. (2003) also 
Aktar et al. (201 1) Bang. J. Anim. Sci. 40 (1\&2): 1 - 7

estimated heritability for birth weight of Sahiwal $x$ Pabna and Freisian x Pabna in an experiment. They found the heritability of $0.37 \pm 0.45$ and $0.32 \pm 0.49$ for Sahiwal $x$ Pabna and Freisian $x$ Pabna, respectively. They also found pooled average heritability of $0.44 \pm 0.30$ for all cattle herd. The estimated heritability for average daily gain $(0.30 \pm 0.10)$ was also in agreement with result by Hoque et al. (2005) for Japanese Black bulls.

The genetic correlations of RFI of bulls with body weights of their progeny were -0.33 for body weight at the start of test and -0.61 for body weight at the finish of test by Hoque et al. (2005). They also concluded that favorable negative genetic correlations between RFI of bulls and body weights of their station progeny indicate that selection for lower RFI (higher feed efficiency) of bulls would lead to an increase in body weights of their progeny. In contrast with the present study, the genetic correlation between RFI of bulls and birth weight of their progeny was closed to zero $(0.08 \pm 0.22)$. Korver et al. (1991) conducted an experiment and estimated the genetic correlations of RFI with daily gain and body weight were close to zero, which supports the present result. The moderate genetic correlations of daily feed intake of bulls with birth weight and average daily gain of their progeny were lower than the reported results. Archer et al. (2002) found feed intake and average daily gain of heifers to be strongly correlated with feed intake $\left(r_{g}=0.94\right)$ and average daily gain $\left(r_{g}=0.72\right)$ of mature cows.

A Genetic correlation between average daily gain and metabolic body weight was $0.96 \pm 0.09$ estimated by Hoque et al. (2005) and the estimated value of the present study was $0.37 \pm 1.24$, which was slightly lower than that correlation. Genetic correlations for the average daily gain and RFI measured in weaners and later in yearlings were ranged between 0.420.95 estimated by Arthur et al. (2001). In the present study genetic correlation for the average daily gain and RFI was negative $(-0.10 \pm 0.18)$. This weak genetic correlation between RFI and average daily gain was not conclusive because of large standard error, which might be due to the small size of the dataset. However, the negative genetic correlation between RFI and average daily gain indicates that it might be possible to decrease extra feed intake of bulls with simultaneous increase in average daily gain of their progeny.

\section{Conclusion}

It can be concluded that metabolic body weight and residual feed intake of crossbred breeding bull has significant impact on progeny early growth performance. In addition, residual feed intake of bulls is independent (zero correlation) of birth weight and weak but negative correlation with average daily gain of their progeny. It indicates that it is possible to decrease residual feed intake of bulls with no adverse effect on progeny early growth performance to improve whole herd production efficiency.

\section{Acknowledgment}

Major funding for this research has been provided through a grant from Bangladesh Agricultural University Research System (BAURES). The logistic support received from the Department of Animal Breeding and Genetics and Dairy Farm of Bangladesh Agricultural University, Mymensingh were gratefully acknowledged.

\section{References}

Archer JA, Reverter A, Herd RM, Johnston DJ and Arthur PF (2002). Genetic variation in feed intake and efficiency of mature beef cows and relationships with post-weaning measurements. Proc. 7th Worl. Congr. Genet. Appl. Livest. Prod. France. 31: 221224.

Arthur PF, Renand BG and KraussC D (2001). Genetic and phenotypic relationships among different measures of growth and feed efficiency in young Charolais bulls. Livest. Prod. Sci. 68: 131-139.

BBS (2009). Bangladesh Bureau of Statistics Yearbook. P. 86.

Das PK, Ali SZ, Islam ABMM and Roy BK (2003). A comparative study of productive and reproductive performance and estimates of heritability for economic traits in different genetic groups of cattle available at Baghabarighat Milk Pocket Area of Bangladesh. Online J. Biol. Sci. 3: 726-740.

Deb GK (2004). Estimation of genetic parameters for some quantitative traits in dairy cattle of Bangladesh. MS thesis, Department of Animal Breeding and Genetics, Bangladesh Agricultural University, Mymensingh. 


\section{Breeding bulls and progeny early growth}

Herd RM, Archer JA and Arthur PF (2003). Reducing the cost of beef production through genetic improvement in residual feed intake: Opportunity and challenges to application. J. Anim. Sci. 81: 9-17.

Hoque MA, Hosono M, Oikawa T and Suzuki K. (2009). Genetic parameters for measures of energetic efficiency of bulls and their relationship with carcass traits of field progeny in Japanese Black cattle. J. Anim. Sci. 87: 99-106.

Hoque MA, and Oikawa T (2004). Comparison and relation among different estimates of residual feed intake for Japanese Black (Wagyu) bulls. J. Anim. Sci. 75: 201-205.

Hoque MA, Arthur PF, Hiramoto K and Oikawa T (2006). Genetic parameters for carcass traits of field progeny and their relationships with feed efficiency traits of their sire population for Japanese Black bulls. Livest. Sci. 100: 251-260.

Hoque MA, Hiramoto K and Oikawa T (2005). Genetic relationship of feed efficiency traits of bulls with growth and carcass traits of their progeny for Japanese Black (Wagyu) cattle. J. Anim. Sci. 76: 107-114.

Khan UN, Olsson A, Philipsson J and Hangsanet K (1992). Sahiwal breed development in Pakistan. Proc. 6th AAAP Anim. Sci. Congr. 1: 171-178.

Koch RM Swiger LA, Chambers D, Gregory KE (1963). Efficiency of feed use in beef cattle. J. Anim. Sci. 22: 486-494.

Korver EEAM, Vos H, Nieuwhof GJ and Arendonk JAM (1991). Genetic aspects of feed intake and feed efficiency in growing dairy heifers. Livest. Prod. Sci. 29: 49-59.
Nahar TN, Islam M and Hasnath MA (1992). A quantitative study on the performance of $F_{1}$ graded cows under rural conditions. AsianAustr. J. Anim. Sci. 5(3): 435-438.

Neumaier A and Groeneveld EG (1998). Residual Maximum Likelihood estimation of covariances in sparse linear models. Genet. Sel. Evol. 30: 3-26.

Oikawa T, Sanehira T, Sato K, Mizoguchi Y, Yamamoto H and Baba M (2000). Genetic parameters for growth and carcass traits of Japanese Black (Wagyu) cattle. J. Anim. Sci. 71: 59-64.

Okine EK, Basarab JA, Goonewardene IA and Mir P (2004). Florida Ruminant Nutrition Conf. 27-38.

Robinson DL (2002). Bias in multiple regression with example from feed efficiency. France. Proc. 7th World Congr. Genet. Appl. Livest. Prod. 31: 221-224.

Robinson DL and Oddy VH (2004). Genetic parameters for feed efficiency, fatness, muscle area and feeding behavior of feedlot finished beef cattle. Livest. Prod. Sci. 90: 255- 270.

SAS (Statisitcal Analysis System) (1998). SAS/ STAT User's Guide, Version 6.12. SAS Institute, Cary, NC. USA. 